\title{
Asymmetric Michael and Aldol Reactions with a Supported Chiral Diamine
}

Polymer-Supported

Synthesis

\section{Key words}

asymmetric catalysis

Michael addition

aldol reaction

organocatalysis

magnetic

nanoparticles

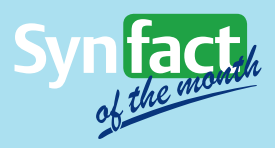

Significance: A magnetic nanoparticle supported chiral aminocyclohexane $\mathbf{1}$ was prepared according to eq. 1. Asymmetric Michael and aldol reactions were carried out in the presence of $\mathbf{1}$ and DMAP in water at room temperature (eqs. 2 and 3 , respectively) to give the corresponding adducts in $\leq 94 \%$ yield and $\leq 100 \%$ ee.

SYNFACTS Contributors: Yasuhiro Uozumi, Go Hamasaka

Synfacts 2016, 12(10), 1097 Published online: 19.09.2016

Dol: 10.1055/s-0036-1589216; Reg-No.: Y11416SF
Comment: The organocatalyst $\mathbf{1}$ was characterized by FT-IR, XRD, TEM, VSM, TG, and elemental analyses. In the reaction of nitrostyrene with isobutyraldehyde, the catalyst was magnetically recovered and reused four times without significant loss of its catalytic performance (fourth reuse: $83 \%$ yield, 95\% ee). 